\title{
Catalpol promotes cellular apoptosis in human HCT116 colorectal cancer cells via microRNA-200 and the downregulation of PI3K-Akt signaling pathway
}

\author{
LAN LIU $^{1}$, HONGWEI GAO ${ }^{2}$, HONGBO WANG ${ }^{1}$, YUAN ZHANG ${ }^{3}$, WEIHUA XU ${ }^{1}$, \\ SEN LIN $^{1}$, HONGJUAN WANG ${ }^{1}$, QIONG WU ${ }^{1}$ and JIANQIANG GUO ${ }^{1}$ \\ Departments of ${ }^{1}$ Gastroenterology, ${ }^{2}$ Trauma and Orthopedics and ${ }^{3}$ Evidence-Based Medicine, \\ The Second Hospital of Shandong University, Jinan, Shandong 250033, P.R. China
}

Received July 17, 2015; Accepted April 21, 2017

DOI: $10.3892 / \mathrm{ol} .2017 .6580$

\begin{abstract}
Catalpol is an effective active ingredient that functions as a diuretic and laxative, and exhibits blood sugar-lowering, liver protective, anti-aging and anticancer effects. In traditional Chinese medicine, catalpol is believed to be Yin nourishing. The anticancer effect of catalpol on human HCT116 colorectal cancer cells were investigated and the mechanism of action was evaluated. Cellular viability was detected using an MTT assay. Caspase-3 and caspase-9 activity, cellular apoptosis and nucleic morphology were analyzed using caspase- 3 and caspase- 9 activity assay kits, flow cytometric assays and DAPI staining assay, respectively. Western blot analysis was used to measure the protein expressions of phosphatidylinositol 3-kinase (PI3K), phosphorylated-protein kinase B (p-Akt) and Akt. Expression of microRNA-200 was detected using the reverse transcription-quantitative polymerase chain reaction. HCT116 cells were incubated with PI3K inhibitors in order to analyze the effect of catalpol on cell proliferation. Catalpol was able to inhibit HCT116 cell proliferation. Furthermore, catalpol induced apoptosis in HCT116 cells, which depended on the increased activities of caspase-3 and -9. In addition, catalpol reduced the expression of PI3K, p-Akt and Akt in HCT116 cells. However, downregulation of PI3K/Akt decreased the viability of HCT116 cells following treatment with catalpol and enhanced microRNA-200 expression. Catalpol promoted cellular apoptosis in human HCT116 colorectal cancer cells through upregulation of microRNA-200 expression, which
\end{abstract}

Correspondence to: Professor Jianqiang Guo, Department of Gastroenterology, The Second Hospital of Shandong University, 247 Beiyuan Street, Jinan, Shandong 250033, P.R. China

E-mail: guo_jianqiang@126.com

Key words: catalpol, human colorectal cancer, microRNA-200, phosphatidylinositol 3-kinase, protein kinase B depended on a downregulation of the phosphatase and tensin homolog/PI3K-Akt signaling pathway.

\section{Introduction}

In recent years, the incidence of colorectal cancer presents an increasing trend (1). According to epidemiological statistics, there are significant differences between colon cancer and rectal cancer in progression and etiology (2). The incidence of colon cancer in Shanghai has increased by $78 \%$ over $\sim 20$ years, while the incidence of rectal cancer has increased by $6 \%$ over the same period. Analysis has demonstrated that the Westernization in lifestyle and diet is associated with the incidence of colorectal cancer (3).

Increasing evidence has demonstrated that microRNAs exhibit endogenous regulatory functions, which serve a regulatory role in ontogeny, cellular proliferation, apoptosis and differentiation, viral replication, reproduction, and tumors to a certain degree. A large number of experiments have demonstrated that the specifically expressed microRNAs are involved in the regulation of cancer development. Recent studies have identified that MDA-MB-231 and BT-549 breast cancer stromal cells, epithelial cadherin transcription factors mediated by microRNA-200 family are upregulated, which is directly associated with ZEB1 translation and indirectly associated with the increased acetylation of histone $\mathrm{H} 3(4,5)$.

In certain diseases, embryo prototype mutation of phosphatase and tensin homolog (PTEN) is $>80 \%$, of which the substrate is a lipid generated by phosphatidylinositol 3-kinase (PI3K) and requires protein kinase B (Akt) activation $(6,7)$. PTEN regulates Akt activity by controlling activated phosphatidylinositol (3,4,5)-triphosphate (PIP3). Therefore, PTEN mutations lead to the loss of the ability to regulate Akt and uncontrolled cellular proliferation, which causes cancerization. PTEN is able to dephosphorylate PIP3, antagonize PI3K activity and reduce the concentration of PIP3 within the cells, thereby inhibiting the activation of Akt, through which PTEN regulates cellular activity (8). In addition, protein phosphatase activity is associated with tumors. Fish oil suppressed cell growth of colorectal cancer by regulating PTEN and nuclear factor- $\kappa \mathrm{B}$ signaling (9). Debroy et al (10) suggested 
that anti-microRNA-221 enhanced the radiosensitivity of colorectal cancer cells by upregulating PTEN. Peroxisome proliferator-activated receptor $\gamma$ induced apoptosis of colorectal cancer cells by upregulating PTEN and inhibiting PI3K activity (11). Isayev et al (12) reported that ribonuclease inhibitor suppresses proliferation and metastasis in colorectal cancer cells by inhibiting the PI3K/Akt signaling pathway.

Catalpol is one of the primary active ingredients in rehmannia, which functions as a diuretic and laxative, and exhibits blood sugar-lowering, liver protective, anti-aging and anticancer effects (13-16). In traditional Chinese medicine, catalpol is believed to be Yin nourishing. Previous studies have observed that catalpol may protect neurons from cytotoxic damage, reducing neuronal apoptosis following cerebral ischemia (17-19). The aim of the present study was to observe the effects of catalpol in colorectal cancer cells, and to investigate its mechanism and determine its therapeutic value in treating colorectal cancer.

\section{Materials and methods}

Reagents. Dulbecco's modified Eagle's medium (DMEM) and fetal bovine serum (FBS) was purchased from Gibco (Thermo Fisher Scientific, Inc., Waltham, MA, USA). MTT was purchased from Sigma-Aldrich (Merck KGaA, Darmstadt, Germany). Caspase-3 and caspase-9 activity assay kits, and the bicinchoninic acid (BCA) protein assay kit were purchased from Beyotime Institute of Biotechnology (Haimen, China). The Annexin V-fluorescein isothiocyanate (V-FITC)/propidium iodide (PI) Apoptosis Detection kit was purchased from BestBio Co. (Shanghai, China). Catalpol was purchased from Sigma-Aldrich (Merck KGaA).

Cell culture. The human colorectal cancer HCT116 cell line was purchased from Union of Basic Medical Cell Center (Beijing, China). HCT116 cells were cultured in DMEM containing $10 \%$ FBS with $100 \mathrm{U} / \mathrm{ml}$ penicillin and $100 \mathrm{U} / \mathrm{ml}$ streptomycin, and cultured at $37^{\circ} \mathrm{C}$ in an atmosphere containing $5 \% \mathrm{CO}_{2}$.

Cell viability assays. HCT116 cells $\left(2 \times 10^{4}\right.$ cells/well) were seeded in 96-well plates and cell viability was detected using MTT. HCT116 cells were cultured with various concentrations of catalpol $(0,25,50$ and $100 \mu \mathrm{g} / \mathrm{ml})$. Following treatment for 24,48 , and $72 \mathrm{~h}, 20 \mu \mathrm{l}$ MTT solution $(0.5 \mathrm{mg} / \mathrm{ml})$ was added into each well and cells were incubated at $37^{\circ} \mathrm{C}$ for $4 \mathrm{~h}$. The culture medium of each well was subsequently removed and $150 \mu \mathrm{l}$ dimethyl sulfoxide was added into each well at room temperature whilst being shaken for $20 \mathrm{~min}$. Absorbance was measured at $570 \mathrm{~nm}$ using a Bio-Rad ELISA reader (Bio-Rad Laboratories, Inc., Hercules, CA, USA). Specific PI3K inhibitors LY294002 and wortmannin were provided by Calbiochem (Merck KGaA). The specific PI3K inhibitors LY294002 $(5 \mu \mathrm{M})$ was incubated at $37^{\circ} \mathrm{C}$ for $1 \mathrm{~h}$ prior to the detection in the wells.

Caspase-3 and caspase-9 activities. HCT116 cells were seeded $\left(1 \times 10^{6}\right.$ cells/well) in 6 -well plates, and the activities of caspase- 3 and -9 were determined using caspase-3 and caspase- 9 activity assay kits. Following treatment for $48 \mathrm{~h}$ with catalpol $(0,25,50$ and $100 \mu \mathrm{g} / \mathrm{ml})$, HCT116 cells were evaluated for hydrolysis of the peptide substrate Ac-IETD-pNA by caspase-3 and -9, resulting in the release of a pNA moiety. Absorbance values were measured with a microplate reader (Bio-Rad Laboratories, Inc.) at $405 \mathrm{~nm}$. The activities of caspase- 3 and -9 were expressed as nmol $\mathrm{pNA} / \mathrm{mg}$ total protein.

Flow cytometric assays for Annexin V-FITC/PI. HCT116 cells were seeded $\left(1 \times 10^{6}\right.$ cells/well) in 6-well plates and the apoptosis of HCT116 cells was measured using the Annexin V-FITC/PI Apoptosis Detection kit (cat no. 556570; BD Biosciences, San Jose, CA, USA) according to the manufacturer' protocol. Following treatment for $48 \mathrm{~h}$ with catalpol $(0,25,50$ and $100 \mu \mathrm{g} / \mathrm{ml})$, HCT116 cells were washed twice with ice-cold PBS and subsequently added to $1 \mathrm{X}$ binding buffer. A total of $5 \mu \mathrm{l} \mathrm{V-FITC} \mathrm{was} \mathrm{added} \mathrm{into} \mathrm{each} \mathrm{well} \mathrm{for}$ $30 \mathrm{~min}$ in the dark. Subsequently, $10 \mu 1 \mathrm{PI}$ was added into each well in the dark. Apoptosis in HCT116 cells was analyzed using flow cytometry (FACSCalibur; BD Biosciences).

DAPI staining assay. HCT116 cells were seeded $\left(1 \times 10^{6}\right.$ cells/well) in 6-well plates and nucleic morphology was tested using a DAPI staining assay. Following treatment for $48 \mathrm{~h}$ with catalpol $(0,25,50$ and $100 \mu \mathrm{g} / \mathrm{ml})$, PBS was used to wash HCT116 cells, and $0.5 \mathrm{ml}$ paraformaldehyde (4\%) was added to each well and cultivated for $30 \mathrm{~min}$ at $4^{\circ} \mathrm{C}$. HCT116 cells were washed twice with PBS, and sodium citrate $(0.1 \%)$ was subsequently added containing $0.1 \%$ Triton X-100 and incubated for $10 \mathrm{~min}$ on ice. DAPI was added to HCT116 cells and incubated for $15 \mathrm{~min}$ at $4^{\circ} \mathrm{C}$ in the dark. Nucleic morphology was viewed under ultraviolet light. HCT116 cells were observed and images were captured using florescence microscopy (Zeiss Axio Observer A1; Carl Zeiss AG, Oberkochen, Germany) at $340 \mathrm{~nm}$.

Western blot analysis. HCT116 cells were seeded $\left(1 \times 10^{6}\right.$ cells/well) in 6-well plates, and the expressions of PTEN, PI3K, phosphorylated (p)-Akt and Akt protein were detected via western blot analysis. Following treatment for $48 \mathrm{~h}$ with catalpol $(0,25,50$ and $100 \mu \mathrm{g} / \mathrm{ml})$, HCT116 cells were washed twice with ice-cold PBS and lyzed for $30 \mathrm{~min}$ on ice in cell-lysis buffer (cat no. FNN0021; Thermo Fisher Scientific, Inc.). Protein concentration was determined using a BCA protein assay kit. Protein samples $(20 \mu \mathrm{g} / \mathrm{well})$ were resolved using $10 \%$ SDS-PAGE. Separated protein was subsequently transferred onto polyvinylidene difluoride membranes (PVDF) membrane for $2 \mathrm{~h}$ at $60 \mathrm{~V}$. The membranes were blocked with 5\% non-fat milk powder in TBS-Tween-20 (TBST) buffer overnight at $4^{\circ} \mathrm{C}$. The PVDF was incubated with anti-PI3K (1:1,000; cat no. GW21071; Sigma-Aldrich; Merck KGaA), anti-Akt (1:1,000; cat no. P0024-1), anti-p-Akt (1:1,000; cat no. BM1612) (both from Boster Biological Technology, Pleasanton, CA, USA) and anti- $\beta$-actin (1:500; cat no. BM0627; Wuhan Boster Biological Technology, Ltd., Wuhan, China) for $2 \mathrm{~h}$ at room temperature. Following three washes with TBST twice for 30 mins, the membrane was incubated with anti-immunoglobulin G secondary antibody (1:500; cat no. BA1054; Wuhan Boster Biological Technology, Ltd.) was added prior to incubation at room temperature for $2 \mathrm{~h}$ with shaking. The bands were detected using the Enhanced 


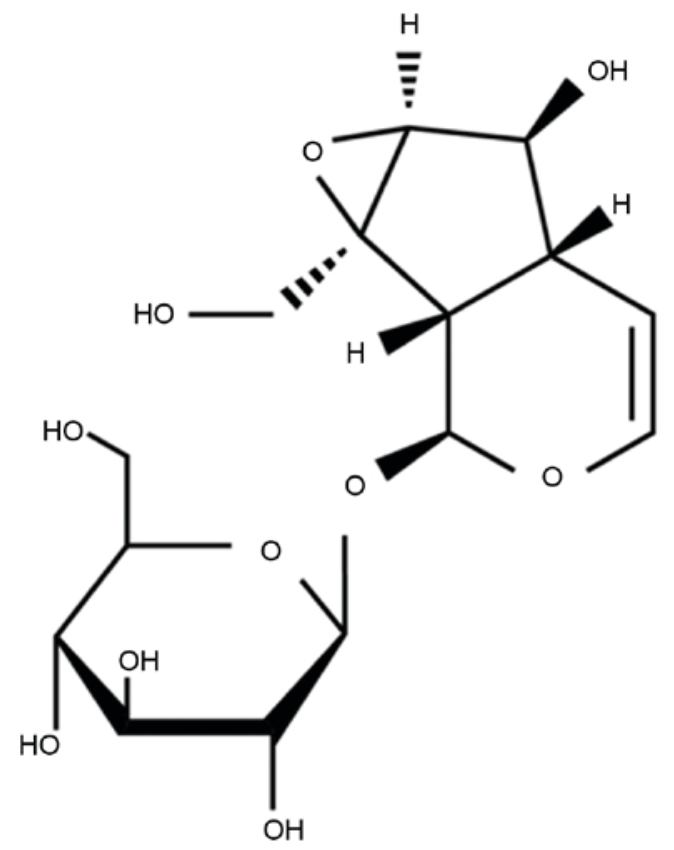

Figure 1. The chemical structure of catalpol.

Chemiluminescence Prime western blotting kit (GE Healthcare Life Sciences, Little Chalfont, UK).

Reverse transcription-quantitative polymerase chain reaction (RT-qPCR) analysis of microRNA-200. Total RNA was extracted from HCT116 cells using TRIzol (Tiangen Biotech Co., Ltd., Beijing, China). MicroRNA-200 was performed using the High Capacity cDNA Reverse Transcription kit with the ABI 7500 qPCR system (both from Takara Bio, Inc., Tokyo, Japan), according to the manufacturer's protocol. The qPCR was performed according to the manufacturer's protocol (cat no. 1725085; Bio-Rad Laboratories, Inc.). The PCR cycling conditions consisted of $93^{\circ} \mathrm{C}$ for $3 \mathrm{~min}$, then 10 cycles at: $94^{\circ} \mathrm{C}$ for $15 \mathrm{sec}, 55^{\circ} \mathrm{C}$ for $15 \mathrm{sec}$ and $72^{\circ} \mathrm{C}$ for $30 \mathrm{sec}$; then 20 cycles at: $89^{\circ} \mathrm{C}$ for $15 \mathrm{sec}, 55^{\circ} \mathrm{C}$ for $15 \mathrm{sec}$ and $72^{\circ} \mathrm{C}$ for $30 \mathrm{sec}$; and an extension cycle at $72^{\circ} \mathrm{C}$ for $10 \mathrm{~min}$. All primers used are purchased from Sangon Biotech (Shanghai, China). The forward and reverse primers for microRNA-200 were 5'-TGCATCATTACCAGGCAGTATTAGA-3' and 5'-CCT CTTACCTCAGTTACAATTTATA-3', respectively. The forward and reverse primers for U6 were 5'-CGCTTCGGC ACATATACTA-3' and 5'-CGCTTCACGAATTTGCGTGTC

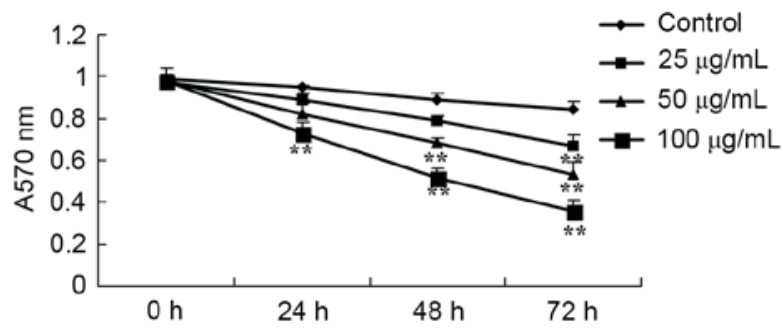

Figure 2. Effect of catalpol on cell viability. HCT116 cells were cultured with various concentrations $(0,25,50$ and $100 \mu \mathrm{g} / \mathrm{ml})$ of catalpol. Following treatment for 24,48 , and $72 \mathrm{~h}, 20 \mu \mathrm{l}$ of MTT solution was added into each well and the cells were incubated at $37^{\circ} \mathrm{C}$ for $4 \mathrm{~h} .{ }^{* *} \mathrm{P}<0.01 \mathrm{vs}$. the control group at the respective time point. A, absorbance.

A-3', respectively. The results were quantified using the $2^{-\Delta \Delta C \mathrm{C}}$ method (20).

Statistical analysis. Experiments were repeated at least three times and were analyzed using SPSS (version 17.0; SPSS, Inc., Chicago, IL, USA). Data are expressed as the mean \pm standard deviation. Differences were tested using the Student's unpaired t-test. $\mathrm{P}<0.05$ was considered to indicate a statistically significant difference.

\section{Results}

Effect of catalpol on cellular viability. The chemical structure of catalpol is indicated in Fig. 1. To investigate the anticancer effect of catalpol on the viability of human colorectal cancer cells, HCT116 cells were treated with catalpol at different concentrations $(0,25,50$ and $100 \mu \mathrm{g} / \mathrm{ml})$ for 24,48 and $72 \mathrm{~h}$, respectively. The absorbances of HCT116 cells were detected using the MTT assay. As presented in Fig. 2, the viability of HCT116 cells was inhibited by treatment with catalpol in a doseand time-dependent manner. These data suggest that catalpol markedly inhibits human colorectal cancer cell viability.

Effects of catalpol on caspase-3 and -9 activities in HCT116 cells. To investigate the activities of caspase-3 and -9 in human colorectal cancer cells, HCT116 cells were treated with different doses of catalpol $(0,25,50$ and $100 \mu \mathrm{g} / \mathrm{ml})$. When the HCT116 cells were treated for $48 \mathrm{~h}$, a significant increase in the activities of caspase- 3 and -9 , following treatment with 50 and $100 \mu \mathrm{g} / \mathrm{ml}$ catalpol, was observed compared with the respective controls (Fig. 3).
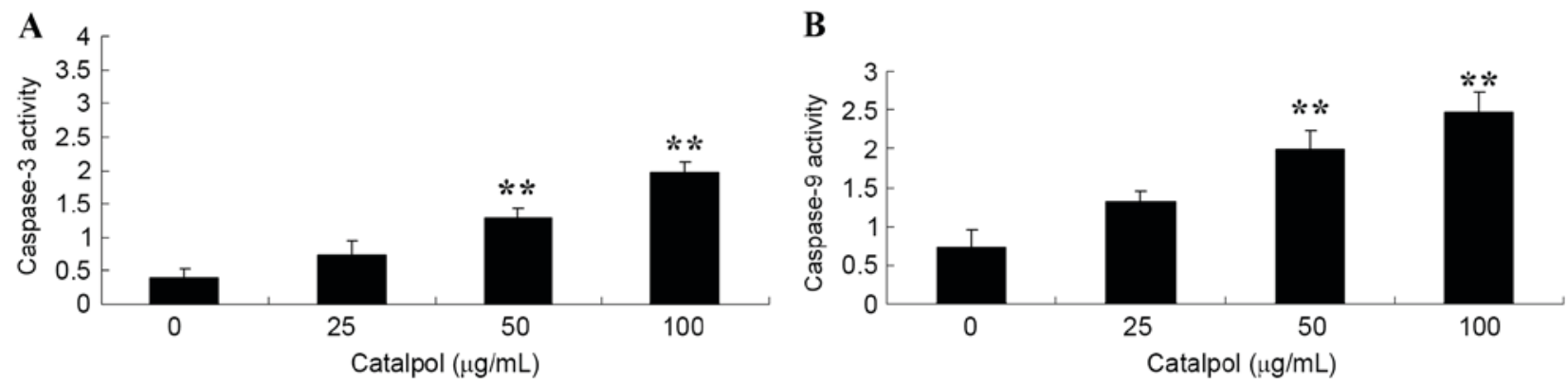

Figure 3. Effects of catalpol on caspase-3 and caspase-9 activity in HCT116 cells. HCT116 cells were seeded (1x106 cells/well) in 6-well plates and treated with catalpol $(0,25,50$ and $100 \mu \mathrm{g} / \mathrm{ml})$ for $48 \mathrm{~h}$. (A) Caspase-3 and (B) -9 activity was subsequently determined. ${ }^{* *} \mathrm{P}<0.01 \mathrm{vs}$. the control group. 
A

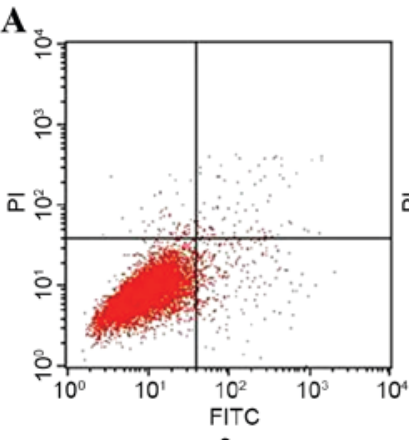

0

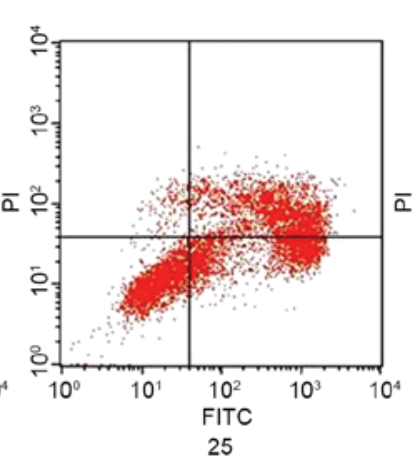

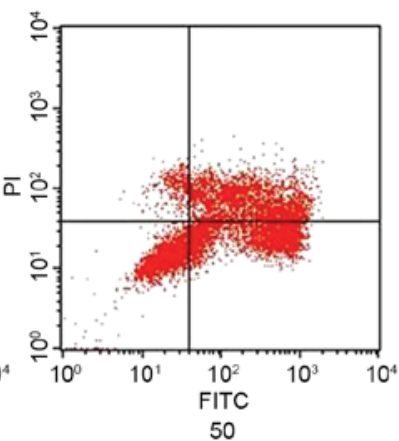

50

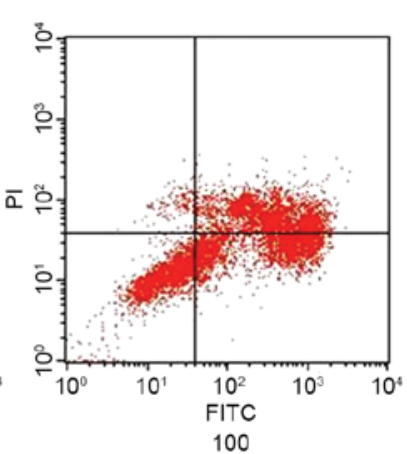

100

Catalpol $(\mu \mathrm{g} / \mathrm{mL})$

B

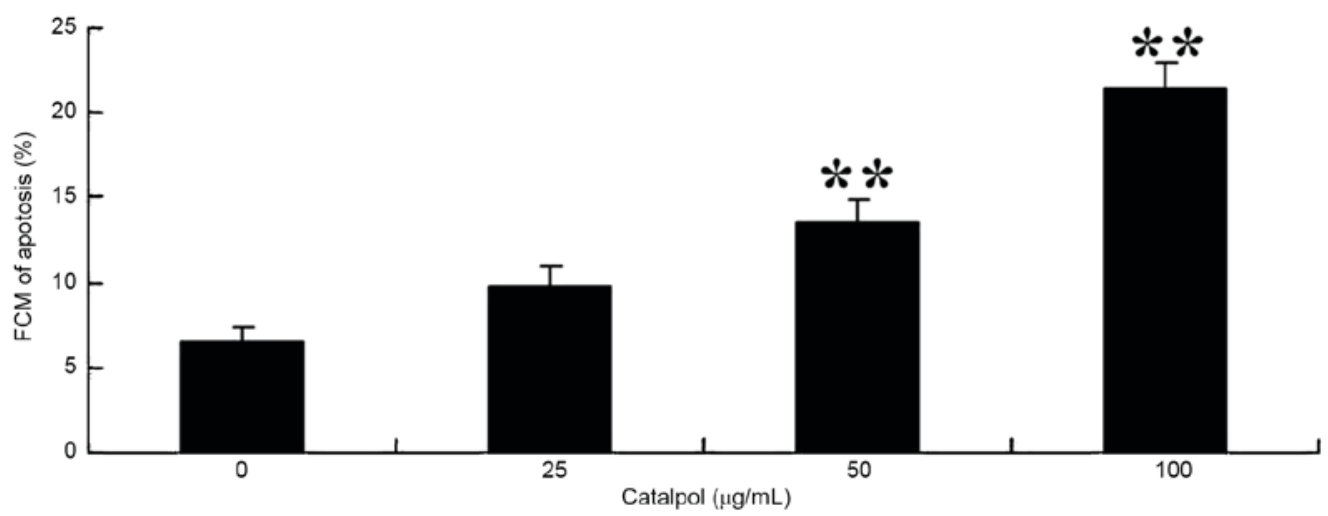

Figure 4. Catalpol induces apoptosis in HCT116 cells. HCT116 cells were seeded (1x106 cells/well) in 6-well plates and treated with catalpol (0, 25, 50 and $100 \mu \mathrm{g} / \mathrm{ml}$ ) for $48 \mathrm{~h}$. (A) Apoptosis was subsequently evaluated. (B) Quantification of apoptotic data. ${ }^{* *} \mathrm{P}<0.01$ vs. the control group. PI, propidium iodide; FITC, fluorescein isothiocyanate; FCM, flow cytometry.

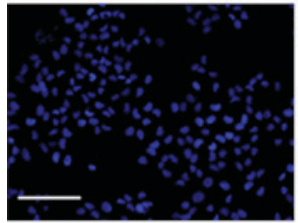

0 catalpol $\mu \mathrm{M}$

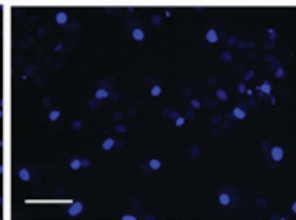

25 catalpol $\mu \mathrm{M}$

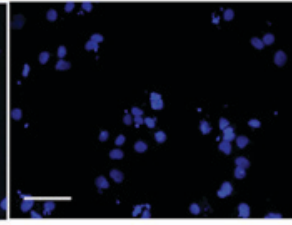

50 catalpol $\mu \mathrm{M}$

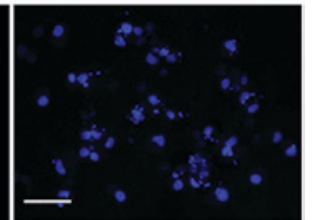

100 catalpol $\mu \mathrm{M}$

Figure 5. Effects of catalpol on the nucleic morphology of HCT116 cells. HCT116 cells were seeded (1x10 cells/well) in 6-well plates and treated with catalpol $(0,25,50$ and $100 \mu \mathrm{g} / \mathrm{ml})$ for $48 \mathrm{~h}$. The nucleic morphology of cells was investigated by DAPI staining (scale bar, $100 \mu \mathrm{m}$ in the first image; scale bar, $200 \mu \mathrm{m}$ in all other images).

Effects of catalpol-induced apoptosis in HCT116 cell. To observe apoptosis in HCT116 cells following treatment with catalpol, the apoptosis ratio was measured using a flow cytometric assay. As presented in Fig. 4A and B, the apoptosis percentage was increased following $48 \mathrm{~h}$ treatment with 50 or $100 \mu \mathrm{g} / \mathrm{ml}$ catalpol.

Effects of catalpol on the nucleic morphology of HCT116 cells. The anticancer effect of catalpol on the nucleic morphology of HCT116 cells was assessed. As presented in Fig. 5, catalpol (50 or $100 \mu \mathrm{g} / \mathrm{ml}$ ) influenced the nucleic morphology of HCT116 cells and accelerated HCT116 cell nucleic apoptosis compared with the control group.

Effects of catalpol on the PI3K-Akt signaling pathway. To further investigate the mechanism of catalpol on the viability and apoptosis of human colorectal cancer HCT116 cells, the expression of PI3K and p-Akt protein was evaluated. Following treatment with catalpol $(0,25,50$ or $100 \mu \mathrm{g} / \mathrm{ml})$ for $48 \mathrm{~h}$, the expressions of PI3K and p-Akt proteins were analyzed by western blotting. The protein expression of PI3K and p-Akt was markedly decreased compared with the control group (Fig. 6).

Effects of catalpol on microRNA-200 expression of HCT116 cell. To further investigate the mechanism of catalpol on proliferation and apoptosis in human colorectal cancer HCT116 cells, microRNA-200 expression was evaluated in HCT116 cells. As demonstrated in Fig. 7, the expression of microRNA-200 was increased following treatment with catalpol $(0,25,50$ and $100 \mu \mathrm{g} / \mathrm{ml})$ for $48 \mathrm{~h}$ compared with the control group. 

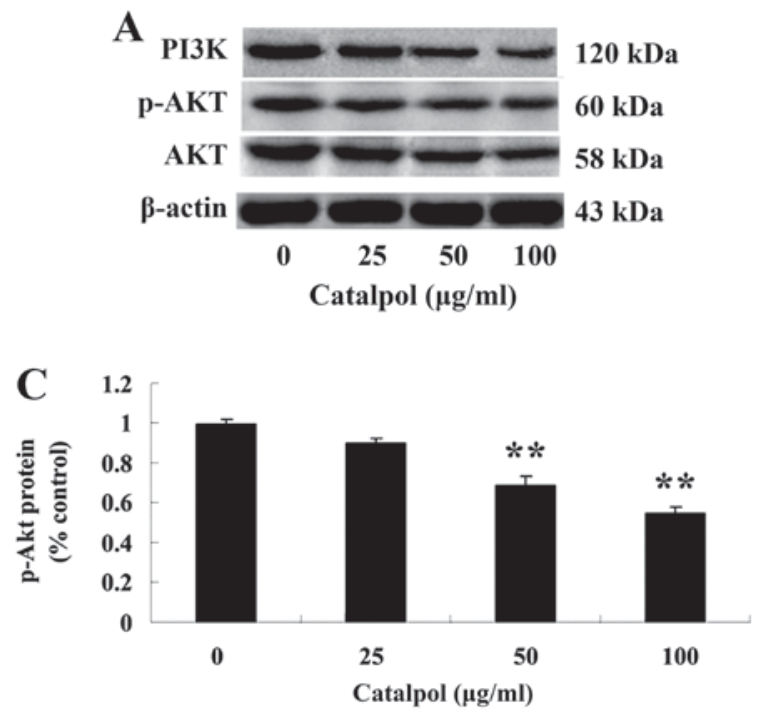
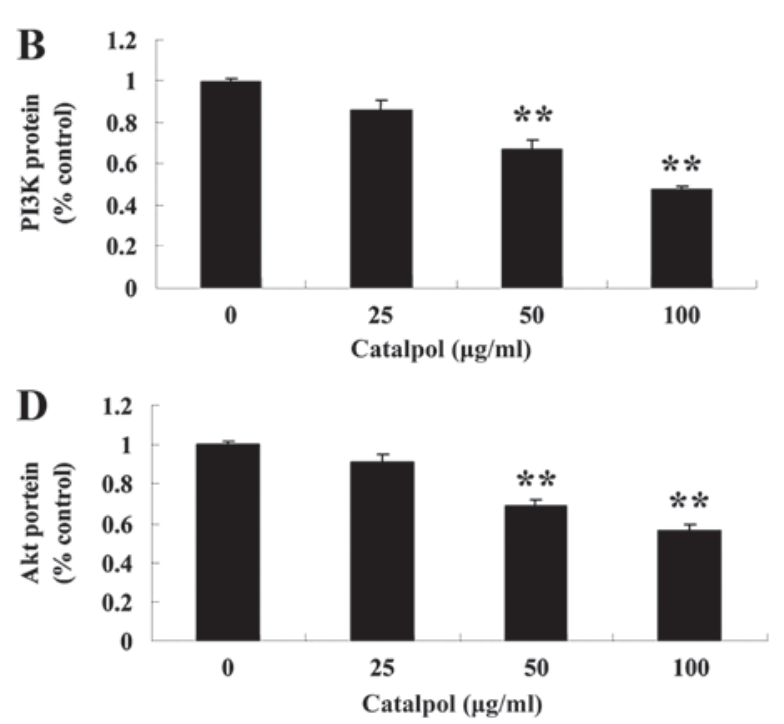

Figure 6. Effects of catalpol on the PI3K-Akt signaling pathway. HCT116 cells were seeded (1x10 ${ }^{6}$ cells/well) in 6-well plates and treated with catalpol (0, 25, 50 and $100 \mu \mathrm{g} / \mathrm{ml}$ ) for $48 \mathrm{~h}$. (A) The protein expressions of PI3K, Akt and p-Akt were measured by western blotting. Quantification of the (B) PI3K, (C) p-Akt and (D) Akt western blotting results. ${ }^{* *} \mathrm{P}<0.01$ vs. the control group. PI3K, phosphatidylinositol 3-kinase; Akt, protein kinase B; p, phosphorylated.

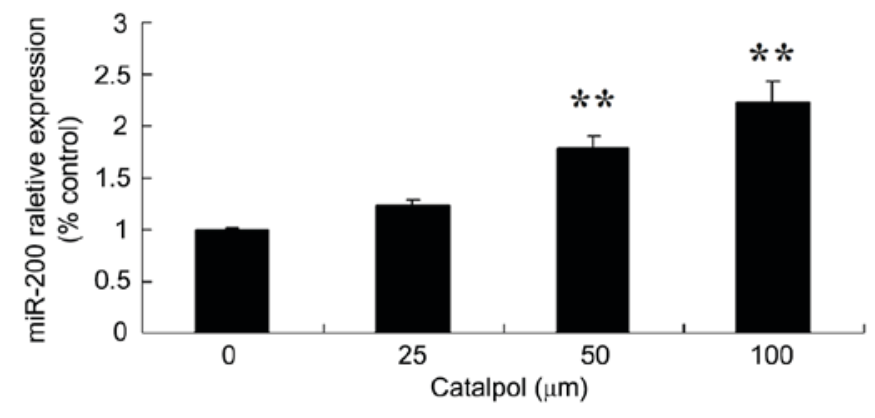

Figure 7. Effects of catalpol on miR-200 expression in HCT116 cells. HCT116 cells were seeded $\left(1 \times 10^{6}\right.$ cells/well $)$ in 6-well plates and treated with catalpol $(0,25,50$ and $100 \mu \mathrm{g} / \mathrm{ml})$ for $48 \mathrm{~h}$. Total RNA was extracted from HCT116 cell using TRIzol and miR-200 expression was quantitatively analyzed. ${ }^{* *} \mathrm{P}<0.01$ vs. the control group. miR, microRNA.

Downregulation of PI3K-Akt following treatment with catalpol and the effect on cellular viability. To investigate the mechanism of catalpol on viability and apoptosis in human colorectal cancer HCT116 cells, PI3K inhibitor (LY294002, $5 \mu \mathrm{M})$ was added to HCT116 cells. The results indicated that the PI3K inhibitor inhibited the PI3K-Akt signaling pathway by suppressing PI3K and p-Akt protein expression in HCT116 cells compared with the catalpol-treated $(50 \mu \mathrm{g} / \mathrm{ml})$ group (Fig. 8A-D). In addition, downregulation of PI3K-Akt further decreased cell viability in HCT116 cells compared with the catalpol-treated $(50 \mu \mathrm{g} / \mathrm{ml})$ group (Fig. 8E).

Effect of downregulation of PI3K-Akt on microRNA-200 expression in HCT116 cells. To verify the mechanism of catalpol on the viability and apoptosis of human colorectal cancer HCT116 cells, microRNA-200 expression in HCT116 cells was detected following downregulation of PI3K-Akt. As presented in Fig. 9, the downregulation of PI3K-Akt enhanced microRNA-200 expression in HCT116 cells compared with the catalpol-treated $(50 \mu \mathrm{g} / \mathrm{ml})$ group.

\section{Discussion}

Colorectal cancer is the most common malignant tumor and it is estimated there were 1.167 million new cases in 2007 worldwide, ranking third among all malignant tumors; 603,000 succumbed to colorectal cancer in the same year $(21,22)$. Currently, colorectal cancer remains a major threat to human health. In the present study, the results demonstrated that the cell viability of human colorectal cancer cells was inhibited by treatment with catalpol. In addition, the treatment of catalpol increased the activities of caspase- 3 and -9 , increased the apoptosis ratio, and accelerated cell nucleic apoptosis in human colorectal cancer HCT116 cells. Lee et al (23) demonstrated that catalpol inhibited the proliferation of ovarian cancer A2780 cells, human epidermoid carcinoma, human rhabdomyosarcoma and transgenic murine L-cells (17).

Increasing evidence has demonstrated that the expression of microRNAs in certain malignant human tissues is altered, including in lung, liver, colon, nasopharyngeal, ovarian and breast cancer. The regulatory role of microRNAs in gastric cancer has also been proven in an increasing number of experiments. In human colon cancer cell lines, microRNA-200 expression is increased and the expression of microRNA-200b decreased following treatment with 5-fluorouracil.MicroRNA-200 inhibits tyrosine-protein phosphatase non-receptor type 12 , which inactivates oncogenes including tyrosine-protein kinase ABL1, proto-oncogene tyrosine-protein kinase Src and GTPase Ras. A previous study demonstrated that microRNA-200 exhibits a regulatory role in the proliferation of gastric cancer MGC-803 cells and that overexpression of microRNA-200 may inhibit the proliferation of gastric cancer MGC-803 cells (24-27). Gao et al (28) reported that catalpol suppresses proliferation and facilitates apoptosis in OVCAR-3 ovarian cancer cells through activation of microRNA-200 and downregulating matrix metalloproteinase- 2 expression. In the 

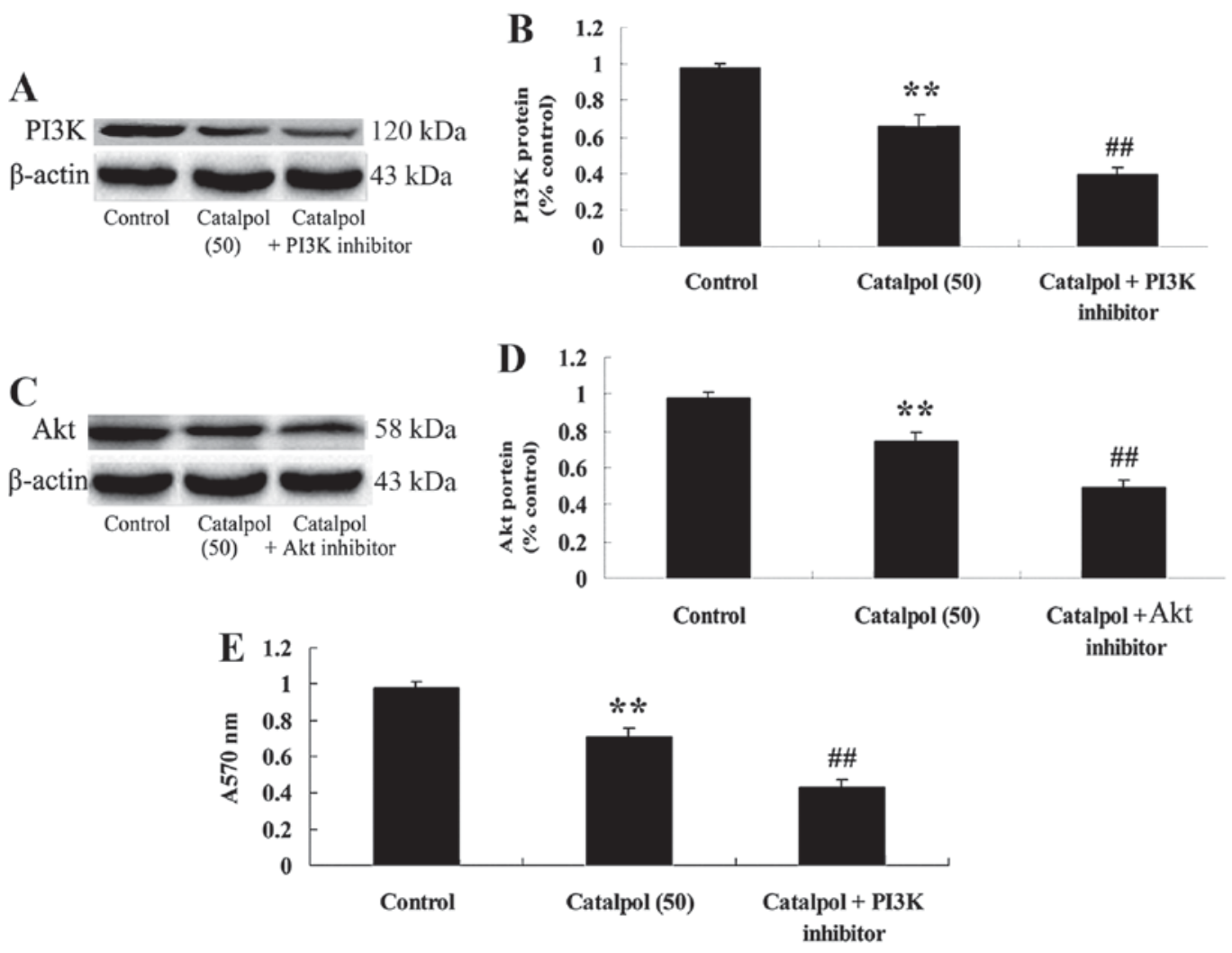

Figure 8. Effect of PI3K downregulation of on cell viability following treatment with catalpol. (A) Western blotting of PI3K following PI3K inhibition. (B) Quantification of PI3K western blotting results. (C) Western blotting of Akt following PI3K inhibition. (D) Quantification of Akt western blotting results. (E) HCT116 cell viability assay following PI3K inhibition. ${ }^{* *} \mathrm{P}<0.01$ vs. the control group; ${ }^{\# \#} \mathrm{P}<0.01$ vs. the catalpol-treated group. PI3K, phosphatidylinositol 3-kinase; Akt, protein kinase B.

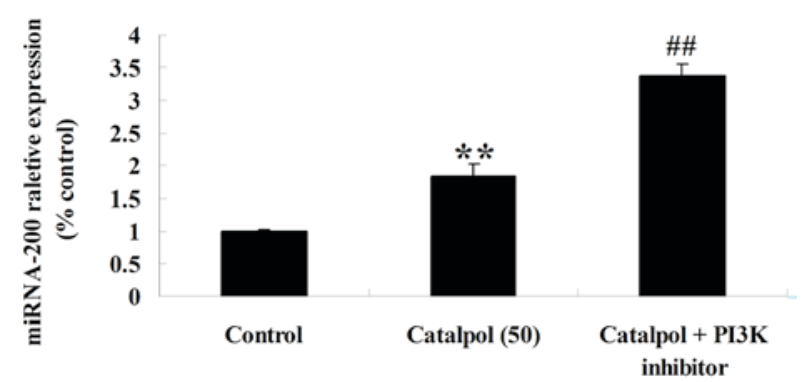

Figure 9. Effect of phosphatidylinositol 3-kinase downregulation on microRNA-200 expression in HCT116 cells treated with $50 \mu \mathrm{g} / \mathrm{ml}$ catalpol. miRNA-200 expression was quantitatively analyzed. ${ }^{* *} \mathrm{P}<0.01$ vs. the control group; ${ }^{\# \#} \mathrm{P}<0.01$ vs. the catalpol-treated $(50 \mu \mathrm{g} / \mathrm{ml})$ group. miRNA, microRNA-200.

present study, similar results were obtained; treatment with catalpol also promoted the expression of microRNA-200 in HCT116 cells.

The PI3K/Akt signal transduction pathway serves an important role in cell proliferation, in which Akt is a downstream target protein of PI3K, and continuous activation of the pathway is associated with tumor development (29). The PI3K/Akt signaling pathway is regulated by a variety of cytokines, in which negative regulator molecules, including PTEN, form primary components (30). In the present study, it was observed that catalpol reduced the expressions of PI3K and p-Akt in HCT116 cells. A PI3K inhibitor decreased the viability of human colorectal cancer HCT116 cell following treatment with catalpol and increased the expression of microRNA-200 in HCT116 cells. Chamnanphon et al (18) reported that catalpol protected oligodendrocyte survival and oligodendrocyte progenitor differentiation through the Akt signaling pathway in rats. Sukasem et al (31) demonstrated that catalpol decreased peroxynitrite formation and consequently exerts cardioprotective effects through the PI3K/Akt signaling pathway in ischemic/reperfusion rats.

In conclusion, catalpol may be used as a natural anticancer drug in human colorectal cancer HCT116 cells. The present study suggests that, administration of catalpol reduced cell viability, increased the activities of caspase-3 and -9, increased cellular and nucleic apoptosis, suppressed the protein expression of components of the PI3K-Akt signaling pathway, and promoted the expression of microRNA-200 in HCT116 cells. In addition, the present study investigated whether downregulation of the PI3K-Akt signaling pathway was due to the effect of catalpol on HCT116 cells. However, treatment with a PI3K inhibitor augmented the effect of catalpol on cell viability and increased the expression of microRNA-200 in HCT116 cells. Therefore, catalpol promotes apoptosis in human colorectal cancer cells through the promotion of microRNA-200 and the downregulation of the PI3K-Akt signaling pathway. These results suggest that catalpol is a promising seed for novel types of anti-tumor agents; however, their molecular targets require further clarification. 


\section{Acknowledgements}

The present study was supported by the Youth Fund of The Second Hospital of Shandong University (grant no. Y2013010024).

\section{References}

1. Pandeló José D, Bartholomeeusen K, da Cunha RD, Abreu CM, Glinski J, da Costa TB, Bacchi Rabay AF, Pianowski Filho LF, Dudycz LW, Ranga U, et al: Reactivation of latent HIV-1 by new semi-synthetic ingenol esters. Virology 462-463: 328-339, 2014.

2. Liu Y, Yin Z, Zhang R, Yan K, Chen L, Chen F, Huang W, Lv B Sun $C$ and Jiang X: MSCs inhibit bone marrow-derived DC maturation and function through the release of TSG-6. Biochem Biophys Res Commun 450: 1409-1415, 2014.

3. Early Breast Cancer Trialists' Collaborative Group (EBCTCG) Effects of chemotherapy and hormonal therapy for early breast cancer on recurrence and 15-year survival: An overview of the randomised trials. Lancet 365: 1687-1717, 2005.

4. Tryndyak VP, Beland FA and Pogribny IP: E-cadherin transcriptional down-regulation by epigenetic and microRNA-200 family alterations is related to mesenchymal and drug-resistant phenotypes in human breast cancer cells. Int J Cancer 126: 2575-2583, 2010.

5. LiX, Roslan S, Johnstone CN, Wright JA,Bracken CP,Anderson M, Bert AG, Selth LA, Anderson RL, Goodall GJ, et al: miR-200 can repress breast cancer metastasis through ZEB1-independent but moesin-dependent pathways. Oncogene 33: 4077-4088, 2014

6. Higgins MJ and Stearns V: Understanding resistance to tamoxifen in hormone receptor-positive breast cancer. Clin Chem 55: 1453-1455, 2009

7. Jiang Y, Gong FL, Zhao GB and Li J: Chrysin suppressed inflammatory responses and the inducible nitric oxide synthase pathway after spinal cord injury in rats. Int J Mol Sci 15: 12270-12279, 2014.

8. Maehr T, Vecino JL, Wadsworth S, Wang T and Secombes CJ: Four CISH paralogues are present in rainbow trout Oncorhynchus mykiss: Differential expression and modulation during immune responses and development. Mol Immunol 62: 186-198, 2014.

9. Zhao S, Zhou L, Niu G, Li Y, Zhao D and Zeng H: Differential regulation of orphan nuclear receptor TR3 transcript variants by novel vascular growth factor signaling pathways. FASEB J 28: 4524-4533, 2014.

10. Debroy A, Vogel SM, Soni D, Sundivakkam PC, Malik AB and Tiruppathi C: Cooperative signaling via transcription factors NF- $\mathrm{BB}$ and AP1/c-Fos mediates endothelial cell STIM1 expression and hyperpermeability in response to endotoxin. J Biol Chem 289: 24188-24201, 2014.

11. Yang Z, Sun D, YanZ, Reynolds AB, Christman JW, Minshall RD, Malik AB, Zhang Y and Hu G: Differential role for p120-catenin in regulation of TLR4 signaling in macrophages. J Immunol 193 1931-1941, 2014

12. Isayev O, Rausch V, Bauer N, Liu L, Fan P, Zhang Y, Gladkich J, Nwaeburu CC, Mattern J, Mollenhauer M, et al: Inhibition of glucose turnover by 3-bromopyruvate counteracts pancreatic cancer stem cell features and sensitizes cells to gemcitabine. Oncotarget 5: 5177-5189, 2014.

13. Sirachainan E, Jaruhathai S, Trachu N, Panvichian R, Sirisinha T, Ativitavas T, Ratanatharathorn V, Chamnanphon M and Sukasem C: CYP2D6 polymorphisms influence the efficacy of adjuvant tamoxifen in Thai breast cancer patients. Pharmgenomics Pers Med 5: 149-153, 2012.

14. Cota GF, de Sousa MR, Fereguetti TO and Rabello A: Efficacy of anti-leishmania therapy in visceral leishmaniasis among HIV infected patients: A systematic review with indirect comparison. PLoS Negl Trop Dis 7: e2195, 2013.

15. Higgins JP and Thompson SG: Quantifying heterogeneity in a meta-analysis. Stat Med 21: 1539-1558, 2002.
16. Lyu J, Yang H, Lang J and Tan X: Tumor necrosis factor gene polymorphisms and endometriosis in Asians: A systematic review and meta-analysis. Chin Med J (Engl) 127: 1761-1767, 2014.

17. Toyama T, Yamashita H, Sugiura H, Kondo N, Iwase H and Fujii Y: No association between CYP2D6*10 genotype and survival of node-negative Japanese breast cancer patients receiving adjuvant tamoxifen treatment. Jpn J Clin Oncol 39: 651-656, 2009.

18. Chamnanphon M, Pechatanan K, Sirachainan E, Trachu N, Chantratita W, Pasomsub E, Noonpakdee W, Sensorn I and Sukasem C: Association of CYP2D6 and CYP2C19 polymorphisms and disease-free survival of Thai post-menopausal breast cancer patients who received adjuvant tamoxifen. Pharmgenomics Pers Med 6: 37-48, 2013.

19. Pu Z, Yuan X, Zhang X, Chen Q and Xie H: Meta-analysis on the association between CYP2D6*10 gene polymorphism and disease free survival of breast cancer patients receiving tamoxifen treatment in Asia. Bangladesh J Pharmacol 9: 652-662, 2014.

20. Livak KJ and Schmittgen TD: Analysis of relative gene expression data using real-time quantitative PCR and the 2(-Delta Delta $\mathrm{C}(\mathrm{T})$ ) method. Methods 25: 402-408, 2001.

21. Lee K, Kim SJ, Kim D, Jo SH, Joong Lee S and Choi SY: Prostaglandin modulates TLR3-induced cytokine expression in human astroglioma cells. Brain Res 1589: 54-60, 2014.

22. Chan SM, Chadwick J, Young DL, Holmes E and Gotlib J: Intensive serial biomarker profiling for the prediction of neutropenic Fever in patients with hematologic malignancies undergoing chemotherapy: A pilot study. Hematol Rep 6: 5466, 2014.

23. Lee S, Pant HC and Shea TB: Divergent and convergent roles for kinases and phosphatases in neurofilament dynamics. J Cell Sci 127: 4064-4077, 2014.

24. Armand-Labit V and Pradines A: Circulating cell-free microRNAs as clinical cancer biomarkers. Biomol Concepts 8: 61-81, 2017

25. Zheng Q, Chen C, Guan H, Kang W and Yu C: Prognostic role of microRNAs in human gastrointestinal cancer: A systematic review and meta-analysis. Oncotarget: Mar 29, 2017 (Epub ahead of print).

26. Tanaka S, Hosokawa M, Yonezawa T, Hayashi W, Ueda K and Iwakawa S: Induction of epithelial-mesenchymal transition and down-regulation of miR-200c and miR-141 in oxaliplatin-resistant colorectal cancer cells. Biol Pharm Bull 38: 435-440, 2015.

27. Ning $X$, Shi Z, Liu $X$, Zhang A, Han L, Jiang K, Kang $C$ and Zhang Q: DNMT1 and EZH2 mediated methylation silences the microRNA-200b/a/429 gene and promotes tumor progression. Cancer Lett 359: 198-205, 2015.

28. Gao N, Tian JX, Shang YH, Zhao DY and Wu T: Catalpol suppresses proliferation and facilitates apoptosis of OVCAR-3 ovarian cancer cells through upregulating microRNA-200 and downregulating MMP-2 expression. Int J Mol Sci 15: 19394-19405, 2014.

29. Luo JB, Feng L, Jiang WD, Liu Y, Wu P, Jiang J, Kuang SY, Tang L, Zhang YA and Zhou XQ: The impaired intestinal mucosal immune system by valine deficiency for young grass carp (Ctenopharyngodon idella) is associated with decreasing immune status and regulating tight junction proteins transcript abundance in the intestine. Fish Shellfish Immunol 40: 197-207, 2014.

30. Jin Y, Desta Z, Stearns V, Ward B, Ho H, Lee KH, Skaar T, Storniolo AM, Li L, Araba A, et al: CYP2D6 genotype, antidepressant use, and tamoxifen metabolism during adjuvant breast cancer treatment. J Natl Cancer Inst 97: 30-39, 2005.

31. Sukasem C, Sirachainan E, Chamnanphon M, Pechatanan K, Sirisinha T, Ativitavas T, Panvichian R, Ratanatharathorn V, Trachu N and Chantratita W: Impact of CYP2D6 polymorphisms on tamoxifen responses of women with breast cancer: A microarray-based study in Thailand. Asian Pac J Cancer Prev 13: 4549-4553, 2012. 